This item was submitted to Loughborough's Research Repository by the author.

Items in Figshare are protected by copyright, with all rights reserved, unless otherwise indicated.

\title{
Rethinking cognition: on Coulter on discourse and mind
}

\section{PLEASE CITE THE PUBLISHED VERSION}

http://dx.doi.org/10.1023/A:1024008104438

\section{PUBLISHER}

(C) Kluwer Academic Publishers (now Springer)

\section{VERSION}

AM (Accepted Manuscript)

\section{LICENCE}

CC BY-NC-ND 4.0

\section{REPOSITORY RECORD}

Potter, Jonathan, and Derek Edwards. 2019. "Rethinking Cognition: On Coulter on Discourse and Mind". figshare. https://hdl.handle.net/2134/15078. 
This item was submitted to Loughborough's Institutional Repository (https://dspace.lboro.ac.uk/) by the author and is made available under the following Creative Commons Licence conditions.

\section{creative
commons}

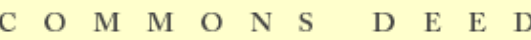

Attribution-NonCommercial-NoDerivs 2.5

You are free:

- to copy, distribute, display, and perform the work

Under the following conditions:

Attribution. You must attribute the work in the manner specified b the author or licensor.

Noncommercial. You may not use this work for commercial purposes.

No Derivative Works. You may not alter, transform, or build upon this work.

- For any reuse or distribution, you must make clear to others the license terms of this work.

- Any of these conditions can be waived if you get permission from the copyright holder.

Your fair use and other rights are in no way affected by the above.

This is a human-readable summary of the Leqal Code (the full license).

\section{Disclaimer 만}

For the full text of this licence, please go to: http://creativecommons.org/licenses/by-nc-nd/2.5/ 


\title{
RETHINKING COGNITION:
}

\section{ON COULTER ON DiscourSe AND Mind}

\author{
Jonathan Potter \& Derek Edwards
}

Discourse and Rhetoric Group (DARG)

Department of Social Sciences

Loughborough University

Loughborough

Leicestershire LE11 3TU

UK

\section{Published as:}

Potter, J. \& Edwards, D. (2003). Rethinking cognition: On Coulter, discourse and mind, Human Studies, 26, 165-181. 


\begin{abstract}
This paper responds to, and comments on, Coulter's (1999) critique of discursive psychology with particular reference to how cognition is conceptualised theoretically and analytically. It first identifies a number of basic misreadings of discursive psychological writings, which distort and, at times, reverse its position on the status of cognition. Second, it reviews the main ways in which cognition, mental states, and thoughts have been analytically conceptualised in discursive psychology (respecification of topics from mainstream psychology, studies of the psychological thesaurus in action, and studies of the way psychological issues are managed). Third, it considers two of Coulter's substantive issues: the role of correct usage and the role of conceptual vs. empirical analysis. A series of problems are identified with Coulter's development of both of these issues.
\end{abstract}


We have admired Jeff Coulter's work for some time. It has provided an important counter to cognitivist thinking in psychology, and has effectively shown the value of Wittgensteinian and ethnomethodological argument in this domain. We were, therefore, disappointed by the failure of his discussion of discursive psychology (Coulter, 1999: 163-81) to live up to his usual scholarly standards. We were disposed to ignore the article's major errors and hope that more constructive discussion would develop elsewhere. However, we have encountered a range of informal and semi-formal references to the paper as providing a definitive account, and dismissal, of discursive psychology. The situation thus needs clarification. This becomes particularly urgent as some linkages (again informal and semi-formal) have been made with the Billig-Wetherell-Schegloff debate (Billig, 1999a,b; Schegloff, 1997, 1998, 1999a,b; Wetherell, 1998). The risk is that, when taken together, an entirely misleading version of the nature of discursive psychology will gain currency with people who might otherwise have found it relevant to their own work. We hope that the critical tone we must adopt here will not distract from what we still see as a basically collegial and communal task. In this commentary we restrict ourselves to Coulter's (1999) paper. There are three themes. First, we identify a range of basic misreadings of discursive psychology. These do not only distort, but at times reverse our position, so it is important to correct them. Second, we briefly review some of the key features of discursive psychology and its approach to mental ${ }^{1}$ states, cognitions, thoughts and so on. Third, we consider some of the broader issues that Coulter raises, particularly with respect to the status of empirical work. 


\section{Coulter's Misreading}

The theoretical and analytic terrain where social constructionist thinking overlaps with discourse analysis, discursive psychology, sociolinguistics, conversation analysis and ethnomethodology is a complicated one. It can be a daunting task, picking a way through this thinking. Positions with similar names or even, sometimes, the same name, may have very different approaches to method and theory in general and to the nature of "mind" in particular. This plainly makes scholarship in this area difficult, but the onus is therefore even more on writers to make sure they are getting things right.

One problem with Coulter's review article is that it covered a range of quite different work that has used terms such as "discursive psychology" and "social construction", including our own writings and also those of Rom Harré and others. It is not always clear which target Coulter has in his sights, but some of his general glosses on "discursive psychology" as a whole (if indeed it is "a whole" in anything other than name) are clearly applicable to Harré's work rather than ours. We intend here to allow Harré to argue his own corner, and to pursue what Coulter has to say about our own programme.

Coulter's basic mistake is to treat discursive psychology, as we have developed it, as an ontological position which explains how an actual thing, mind, is produced through discursive construction and, moreover, something revealed through talk:

a thesis which proposes that the human mind and its various properties are generated in and through discourse: in essence, the "mind" is revealed in and through analysable features of the things that people say and do through their talk, especially through their talk about the mental (Coulter, 1999: 163, original emphasis).

This is simply wrong. However applicable it might be to work by Harré, or more obviously by constructionist psychologists such as Vygotsky, Bruner or Piaget, it is at odds with the many published statements we have made about our work, including statements in books reviewed by Coulter, and it is also entirely inconsistent with the way the approach is 
developed in research practice. For us the question is how could Coulter have got it so wrong?

With respect to his discussion of our book Discursive Psychology (Edwards \& Potter, 1992) one of the main problems is that he confuses our critical targets with our own position. Near the start of the book we make some observations about theoretical differences between cognitivist and social constructionist researchers. We do this precisely to mark out the difference from a discursive psychological approach:

it is not our intention in this book to develop these [cognitive and social constructionist] sorts of arguments. Here we intend to bracket, or set aside, the issue of reductionism and origins in favour of an orientation to method and analysis. That is, our concern will be to examine how participants in talk address the kinds of concerns that cognitive and social psychologists have raised (Edwards \& Potter, 1992: 19).

Yet Coulter quotes from just four paragraphs before this, where we are glossing one of the two groupings that we are distinguishing ourselves from, and treats it as our position.

It is worth re-quoting part of Coulter's own quotation of us, along with his gloss, to give a flavour of both his mistake and the vigour with which he is pursuing it. He writes: They write:

Cognitive processes [sic.], on this [social-constructionist-JC] view, are not the springs of human sense and action, however much our everyday concepts of mind may get to be refined [sic.] by experimental psychology and cognitive science. Rather they are ideas generated within cultures, conceptions of sense, action and motive [sic.] that people invent to mediate their dealings with each other, to engage in social forms of life. (...)

This passage already concedes far too much: it concedes the existence of putative "cognitive processes" (whose nature is left unspecified), as well as the contentious notion that theoretical psychologists can "refine" our "everyday concepts of" the mental. Exactly how this procedure might work is also neither specified nor defended. (Coulter, 1999: 164. The bracketed insertions are all Coulter's). 
Let us make a number of observations about what is going on here. In reporting two positions (cognitivism and social constructionism), we are not thereby committing ourselves to them. Rather the contrary, we were in the first chapter of a book that developed some rather different views! This is a pretty conventional way of starting a book. In reporting a view on cognitive processes, we are not thereby committed to the existence (or not) of such things. Nor did we endorse the idea that experimental psychologists are actually "refining everyday concepts" - that was the sense of "however much", that we were setting aside that assumption as outside of the argument at that point. In fact, much of the book is precisely raising questions about such claims and assumptions.

Further, given that the terms "cognitive processes", "refined", and "motive" are a central part of the discussion, it seems odd that their very use is dubbed erroneous by Coulter. The sprinkling of "sics" at the mere use of those words, as if listing glaring errors, is merely annoying. Many of the words at which Coulter pokes his tongue in this way appear in our glosses on others' views, or as the very terms under examination. Indeed, he uses them frequently himself and, quite properly, not always inside scare quotes. It would be easy, if equally pernicious, to quote Coulter on "the rules of use of the mental predicates" (ibid.: 167) and simply insert "[sic]" after "mental", as if somehow catching him out.

Given that Coulter is confusing our report of a social constructionist perspective with our own argument, it is perhaps not surprising that he goes on to use our report of the kinds of counter arguments that cognitive psychologists use against it, as a counter argument against us. Yet it might surely have given him pause to wonder why we were explicitly and cheerfully "selling out the anti-Cartesian and anticognitivist position" (Coulter, 1999: 164) in that way. The answer (as we have already quoted) is right there a few lines later: we were attempting to develop an approach that was not susceptible to those critiques. At this point in the book we confessed some past use of the kind of social constructionist arguments from 
which we then wished to distance ourselves; a point that Coulter quotes, as if we were continuing with those arguments. We could cite more confusions of this kind, but we hope that these are sufficient to make the point.

Coulter treats all bracketing-off of mental issues to be a concession of the "ontological status attributed to the "mental' and the "cognitive"', and therefore an undercutting of the chance of being "taken at all seriously" (Coulter, 1999: 165). In one sense this is an issue of rhetoric (and no less important for that). We have been attempting to engage cognitive psychologists and social cognitive psychologists in constructive debate for some time. Starting our book off with an assertion that their favoured topics of study simply do not exist is not likely to foster productive debate, even when it is backed up by citations of great philosophers such as Wittgenstein. Note that generating such a dialogue has not committed us to "theoretical dilution" or "Cartesian concessions". Indeed, we are more commonly accused of extremism or obstinacy!

Let us move on to Coulter's discussion of Edwards (1997). As Coulter notes this is a more advanced treatment of the issues. Several years of further thinking and research have gone into it. It is therefore somewhat surprising that it is not taken as the more up to date and definitive guide. No matter. The gloss on this work continues the misunderstandings of the earlier one, and compounds them with new ones. Again it is worth quoting both the quote and the gloss:

Mind and reality are treated analytically as discourse's topics and business, the stuff the talk is about, and the analytic task is to examine how participants descriptively construct them (Edwards, 1997: 48)

The problem with such a formulation is that it restricts the appeal to ordinary language conceptualisation to that which is revealed only in a fully topical and explicit manner: the "mental" is thus to be construed solely in terms of what people say about it (Coulter, 1999: 166). 
We fail to see the restriction that Coulter identifies. Indeed, insofar as discursive psychology is a programme, analysis of practices using mental words is just one of its elements. We will say more about this shortly, but it is not something that is hard to discover. For example a considerable part of the 1992 book, of which Coulter is so critical, re-works psychologists' technical categories of memory and attribution in terms of descriptions of events, actions, people and, sometimes, mind. ${ }^{2}$ Very little of this is direct talk about mental states (however construed); it is mostly event descriptions, uses of categories and narrative devices, ways of implicating, handling or managing common sense psychological concerns (such as motive, memory, intentions) rather than "talking about" them. It starts to become difficult to believe that Coulter has actually read the book.

Coulter goes on to say this about discourse, as part of a contrast with the notion of language games:

Discourse, however, while indeed it obviously involves the deployment of concepts, is more generally understood in these texts as "talk about...X", whether X is a mental or any other "topic". Discourse is, within linguistics, a trans-sentential unit of the use of language (Coulter, 1999: 166).

Let us put on one side the claim about concepts, which is potentially a major source of confusion given their typical cognitivist interpretation in psychology, and it was to academic psychology that our arguments were addressed. The odd thing is the claim that "these texts" (ours?) understand discourse as "talk about...X". This may be true of some more Foucaultian inspired discourse work; but ours is more influenced by linguistic philosophy, ethnomethodology and conversation analysis. We have explicitly contrasted our work with the linguistic take on discourse as "trans-sentential units". Again, Coulter seems to take everything called "discourse analysis", which is a notoriously heterogeneous and unrelated collection of approaches, as covering the same things. It is an ironically odd, referential notion of what words mean, for him to have fallen into. 
At the start of Discursive Psychology we gave a gloss that is worth repeating, although with added emphasis to highlight Coulter's failure to adequately capture what we suggested:

The focus of discursive psychology is the action orientation of talk and writing. For both participants and analysts, the primary issue is the social actions, or interactional work, being done in the discourse. But rather than focussing on the usual concerns of social interactional analyses, such as the way social and intergroup relationships are conducted (through forms of address, speech accommodation, etc.), or how "speech acts" might be identified, the major concern in this book is epistemological. It is with the nature of knowledge, cognition and reality: with how events are described and explained, how factual reports are constructed, how cognitive states are attributed. These are defined as discursive topics, things people topicalize or orient themselves to, or imply, in their discourse. And rather than seeing such discursive constructions as expressions of speakers' underlying cognitive states, they are examined in the context of their occurrence as situated and occasioned constructions whose precise nature makes sense, to participants and analysts alike, in terms of the social actions those descriptions accomplish (1992: 2, emphasis added).

Coulter goes on to pick out further quotes from Edwards (1997) with the aim of showing that it involves an inherent Cartesian dualism. However, as before, his glosses on these quotes fail to grasp their role in speaking to cognitive psychologists without starting by dismissing their topic. We have learned that that is a way to get nowhere fast.

The key point, and the point that is most significant to us, is that Coulter pays no attention to the analysis (neither specific examples nor general practice) through which discursive psychology is defined and exemplified. Surely the most effective and accurate way to understand our position is not to focus on our abstract claims about it (which are necessarily directed at a range of different audiences) but to consider how those claims are cashed out in practice. Whatever we say about it, however much we use words that might be interpreted in a cognitivist fashion, does our practice reveal a Cartesian split between an inner world of cognition and an outer world of language and action? We suggest that if Coulter 
looks at these he will find a non-Cartesian position, although perhaps not precisely the one he favours.

Overall, we are disappointed by Coulter's reading of our work. However, we hope we have highlighted some of the errors here (we could go on!). For the rest of this discussion we prefer first to overview some elements of a discursive psychological approach to cognition, mental states and similar "mental" phenomena, and then consider some of the interesting substantive claims that Coulter makes.

\section{Themes in Discursive Psychology}

General programmatic features of discursive psychology have been outlined in a number of places. The quote above from Edwards \& Potter (1992) is still apposite in highlighting some of those features. Compact recent summaries are available in Edwards \& Potter (2002) and Potter \& Edwards (2001a,b). However, what is centrally at stake in this article is the status of cognition (or "cognition"). Let us state clearly and explicitly that discursive psychology deals with cognition in three related ways.

1. Respecification and critique. The focus here is on the respecification of psychological topics in terms of situated discourse practices. This work takes topics from mainstream psychology and reworks them in terms of practices done through talk and text. For example, Edwards \& Potter (1992) includes a reconsideration of Ulric Neisser's well known naturalistic study of John Dean's memory as illustrated in the Watergate hearings and the Nixon Whitehouse tapes ${ }^{3}$. We highlighted the way features of the discourse, which were taken by Neisser as documents of various underlying levels of information processing, could be better understood as elements of, or consequences of, particular discourse practices. Work of this kind has taken a critical stance with respect to mainstream cognitive psychology. However, it does 
this not by arguing for the non-existence of mental objects, nor through research showing their non-existence. We believe that neither of these approaches has been and will be very effective. Rather our approach is methodological and epistemic. We have done studies that cast doubt on the taken-for-granted methodic production of mental entities in cognitive psychological research.

2. The psychological thesaurus. The focus here is on the situated, occasioned, rhetorical uses of the commonsense lexicon of psychology. This involves a study of the practical use of terms such as angry, jealous, believe, like, feel and so on. For example, expressions such as "I don't know", or "your angry stage" have been studied for the local contrasts and interaction business they perform (e.g. Edwards, 1995; Potter, 1998). These studies focus on actual materials, records of interaction in everyday and institutional settings.

3. Managing psychological implications. Much discursive psychological work has studied the way psychological themes are managed and handled without necessarily being overtly labelled. We have studied how agency, intent, doubt, belief, prejudice, and so on, are built, made available, or countered "indirectly", through descriptions of actions, events, objects, persons or settings. This has been a key feature of the first type of discursive psychology, where attributions of intent and blame are shown to be handled, not by overt descriptions of intent or motive, but through what look like (or are produced as) straightforward event descriptions. This is central in our exploration of "fact and accountability" (Potter \& Edwards, 2001), where we show how factual descriptions are used to implicate a range of psychological states and attributions, and vice versa. Again, such studies work with actual materials rather than invented or hypothetical examples. 
All three of these themes in discursive psychology are at odds with the customary approach of modern cognitive and social psychology. In numerous debates with more mainstream cognitive psychologists and social cognition researchers in formal, semi-formal and informal settings, we have not found that they have had any trouble recognizing and opposing the central anti-cartesian thrust to our proposals.

Our work is also different in certain important respects to much current thinking in “social constructionism” (e.g. Harré \& Gillett, 1994; Shotter, 1993). These differences are often centred on issues of method and mind. They are sometimes complex, and we will not try to explore them here. However, one of us has produced a book length reconsideration of constructionism from a broadly discursive psychological approach (Potter, 1996). This highlights our epistemic rather than ontological take on constructionism, and identifies points of contrast with other constructionist approaches. Nevertheless, we hope we have done enough to show that Coulter's simple reduction of our work to social constructionism in general is a mistake.

What we have tried to do, then, is briefly illustrate the coherence of discursive psychology as a programme of work, and to show how Coulter's criticisms are either wrong or based on a confused version of what the programme is. In the final section of this article we will consider some of the substantive arguments that Coulter has raised.

\section{Substantive arguments}

We will try to end this discussion on a more constructive note. Among other points he makes, Coulter raises two important and connected issues. The first concerns the question of correct or incorrect everyday usage, and the related possibility of theoreticians or analysts checking or correcting such usage. The second issue concerns the conceptual or empirical 
basis that is appropriate for proper analysis, and discursive psychology's take on that. We quote Coulter at some length to show how he relates these issues together.

...it may be argued that analysts of discourse and their allies, the "discursive psychologists", are engaged in a purely empirical enterprise. When they discuss "theoretical" issues pertaining to human mentality, however, inductive methods alone are unhelpful. We do not need an empirical sample of instances of what various people happen to say about mental concepts and predicates, but rather we need examples of their use in engaged activities, what Wittgenstein (1968: para. 122) called an "ubersichtlichkeit Darstellung" - a "perspicuous representation", involving the adducing of arrays of richly-described cases of conduct and relevant circumstances in and through which the concept or conceptual structures of interest can be revealed. Abstracted bits of empirically-sampled "discourse" will not help us here if they are chosen at random, since it is clear that people can, and do, misuse words on occasion, and may even do so in ways which are not locally corrected nor challenged by participant interlocutors. Hence, although, of course, real-world cases are our preferred forms of instances, no purely empiricist or distributional criteria will suffice for our purposes of clarifying the grammars of our concepts: for that, we require to distinguish between intelligible vs. unintelligible uses, correct vs. incorrect, appropriate vs. inappropriate, etc... (Coulter, 1999: 171, original italics).

Let us start with two brief passes though this quote. First, let us note and discard some of the rhetorical finessing. We do not need to take seriously the idea of studying examples of what people "happen to say" which have been "chosen at random" using "empiricist" criteria. We are not familiar with too many analysts of discourse or otherwise who are made of quite so much straw. Second, we may note and correct the reiteration of the misreadings of discursive psychology that have been documented in the previous two sections: in particular, the idea that discourse researchers work with what people say about mental concepts. Putting those two points to one side, let us consider the key issues of correct usage and empirical research. They are at the nub of what distinguishes our approach from Coulter's. 
With respect to correct and incorrect usage, we do not see the role of discursive psychologists as identifying proper and improper usages of "mental words". We are interested in practices that use mental terms, and how those words are operating in those practices. Criticizing participants for their possible misuse of words seems an odd thing for an analyst to do, echoing, somewhat ironically given the rejection of Cartesian cognitivism, the Chomskyan principle that has created such a profound and consequential difference in the materials taken seriously by cognitive psychologists and conversation analysts. This warning, that participants may misuse their own terms, is notably unexplored via any cases where it "perspicuously" happens. But it is also a dangerous principle on which to found an analytical methodology. It may be, though it is unclear, that Coulter's worry is restricted to the errors that people can make when offering disembedded theoretical assertions about language and mind; but such dubious items are not the stuff of DP.

If we embark on a study of some kind of therapy or counselling talk, it is very likely to be imbued with what Coulter criticizes as "members' own appropriations of cognitivist and mentalistic theorizing" (1999: 166). There could be a lot to complain about, if we were aiming to criticize all such "appropriations". However, from our perspective it is perfectly coherent to study that interaction as a practice in broad terms and, more specifically, to consider the use of "mentalistic theorising" in that practice. Such an analysis does not require judgements about the correctness of the language use; rather it requires systematic study of how the practice is organized. That their language use is intelligible in some sense or other is, in fact, required in order for Coulter to assert that people are mistaken.

We have argued that discursive psychology is conducted most coherently from a stance of methodological relativism, similar to that used in many studies of science (e.g., Collins, 1983; Woolgar, 1988) ${ }^{5}$. That is, for analytic purposes we are indifferent to the correctness, accuracy or whatever of what people are saying. This allows studies of family 
therapy in AIDS counselling (Peräkylä, 1995), or of stories about experiences with ghosts and poltergeists (Wooffitt, 1992), to be conducted without (a) the researcher having to believe in, say, Milan School family therapy or a paranormal world, and (b) having to be at least as expert as the participants in the relevant universe of ideas.

The disagreement here is a sharp one. For Coulter, any discourse purporting to be referring to private mental states is simply mistaken, and should be corrected. For us, while recognizing the value of linguistic philosophy, and drawing on it in theoretical debates with psychologists from other approaches, we do not see it as appropriate to criticize member's practices in the way suggested. For example, there may be practices where there is some point to the idea of referring to private mental states, though not as the analyst's favoured theory of language and mind. Here the status of reference to internal mental states is not something to be refuted, even though it is conceptually refutable, but rather, studied as a practice within public forms of life. People may sometimes talk as if, or on the proposed and oriented-to basis, that their words are expressing inner thoughts and feelings. It is a basis and orientation found in clinical psychology, for example, if we approach clinical attributions as studiable practices rather than rival theories of "mind". But it is found also in everyday talk, where again it is available for study as a social practice. It is also something that can be countered, not only by philosophical argument, but as part of everyday practices. People may point to inconsistencies, or to evidence to the contrary, or to disagreements, or to the speaker's proposed strategic aims, and thus challenge any claim that they are merely reporting what they think.

Coulter writes about how "mind" is not a "thing" of any kind that could be "talked into being" (1999: 169). We have already noted that Coulter has ignored a crucial distinction between ontological and epistemic constructionism. We are not proposing some "thing" that is talked into being. Rather we are concerned with the operation of practices and the terms in 
those practices. However, the interesting thing here is how Coulter argues his point as it relates to the question of the status of empirical and conceptual research. Note his use of invented, disembedded examples.

"Mind" is either a lay notion, variously deployed, or a theorist's reification. When vernacularly used, it is harmless enough: "she's on my mind", "it slipped my mind", "he changes his mind", and so forth, all have clear-cut, contextually-dependent vernacular paraphrases, none of which commit a speaker to any form of Cartesianism or neo-Cartesianism whatsoever. (1999: 169, original italics).

The interesting thing is this notion of "paraphrases". We acknowledge the value of paraphrases, of the kind that Coulter invokes, in making analytic-philosophical arguments. For example, Wittgenstein (1958) used them to demonstrate the impossibility of a "private language", and (cf. Sacks, 1992) to show how any set of linguistic concepts and practices in use in any society have to be learnable via their situated uses. But paraphrases are generally used (controversially) in philosophy, linguistics and stylistics (e.g., in standard treatments of "formal" and "informal" ways of saying "the same thing"), in ways that cut across situated, indexical, contrastive uses of particular expressions. We may ask, what makes a paraphrase something equivalent in meaning? How does its "contextually-dependent" nature retain its status as a paraphrase? Is a notion of logical equivalence adequate here? What is the basis of choice between these ostensible paraphrases, or are they generally equivalent for all practical purposes?

Coulter's appeal to paraphrases works by remaining in the realm of disembedded conceptual stipulation. Yet surely the entire field of conversation analysis speaks to the dubiousness of any notion of a paraphrase as a useful analyst's category. It can only be a discourse practice to claim such a status for a description, that it is effectively equivalent to another; it can only be a defeasible, situated proposal or orientation of some kind, and worthy of study as such. 
Of course, there are already some relevant studies, such as Heritage and Watson (1979) on "formulations", a notion developed from Garfinkel and Sacks (1970) on the practice of "saying in so many words". When one set of words is offered in practice as equivalent to, or as the essence of, another set of words, there is likely to be something going on, some practice that the notion "paraphrase" merely obscures. In fact, being able to say something such as "he changes his mind" rather than, say, "he is inconsistent" (or whatever non-mentalistic paraphrase one might prefer), can have its uses. We can start to hear a different range of accountability across such expressions. Indeed they are different descriptions, different words that can do different things, which is probably why they are available. A useful way into seeing what they do, would be to collect a set of instances of people offering re-descriptions that purport to be equivalent in some way. We would expect such a study to evaporate the notion of "paraphrase" rather quickly.

Coulter objects to Edwards's (1997) use of the phrase "an act of remembering", as if this implied underlying cognitions, ignoring the fact that the term was carefully chosen in contrast to what cognitive psychologists call "memory" (Edwards, Middeton \& Potter, 1992) precisely to highlight the action of talking about the past, against expressing mental states. Coulter's preferred, ostensibly non-mentalistic paraphrase is "an act of recounting a recollection" (1999: 168) which, it seems to us, merely begs the same questions. The Oxford English Dictionary (1992, $2^{\text {nd }}$ edition on CD-Rom), though clearly not written by Ryle, glosses "recollect" as "to call or bring back (something) to one's mind". Whatever the merits of that definition, it is clear that merely substituting "recollection" for "remembering" fails on all counts. Indeed, the notion that a "recollection" requires to be "recounted" suggests that it might be something other than the act of recounting; Coulter's preferred terminology seems even more problematical than ours. See Edwards \& Potter (in press) for further discussion. 
Let us move on from considering problems with Coulter's notion of a paraphrase to the kind of (made up) examples that he asks us to consider. Again, we recognize the central value of invented examples in theoretical linguistics and in philosophy. However, our preferred approach is to look for actual cases in actual materials. Whether this should be considered an "empirical" move or not is unclear; we certainly reject the implication that it implies a commitment to the philosophy of "empiricism". Coulter also stresses the importance of such materials: "of course, real-world cases are our preferred forms of instances" (see the larger quotation above), but his concern is to apply "grammatical" analysis which will "distinguish between intelligible vs. unintelligible uses, correct vs. incorrect, appropriate vs. inappropriate, etc., uses vs. misuses" (1999: 171). Yet his preference is not displayed in his article by a rich use of "real-world" cases. On the contrary, he produces invented, normatively intelligible examples in which people are taken to "assert" (166) things or make "empirical claims" (172).

One of the problems of using idealized examples (i.e., definitively correct ones, free from the vicissitudes of what Chomsky calls "performance"), as examples of actual social practices, is that it easily lends itself to a strange notion of what people are up to when they say things. It tends towards a treatment of people as making definitive assertions, and as talking theoretically. For those very reasons, as well as the avoidance of situated contingencies, it is an analytic practice much favoured in cognitivist treatments of language and meaning.

Nevertheless, the following is a "real-world" case. It is taken from a telephone helpline for reporting child abuse. The caller has been describing problems with her male partner that may relate to events in his childhood. We are particularly interested in the arrowed turn (line 18) where the child protection officer (CPO) talks about something in the back of the caller's mind. 


\section{NSPCC BN $15^{6}$}

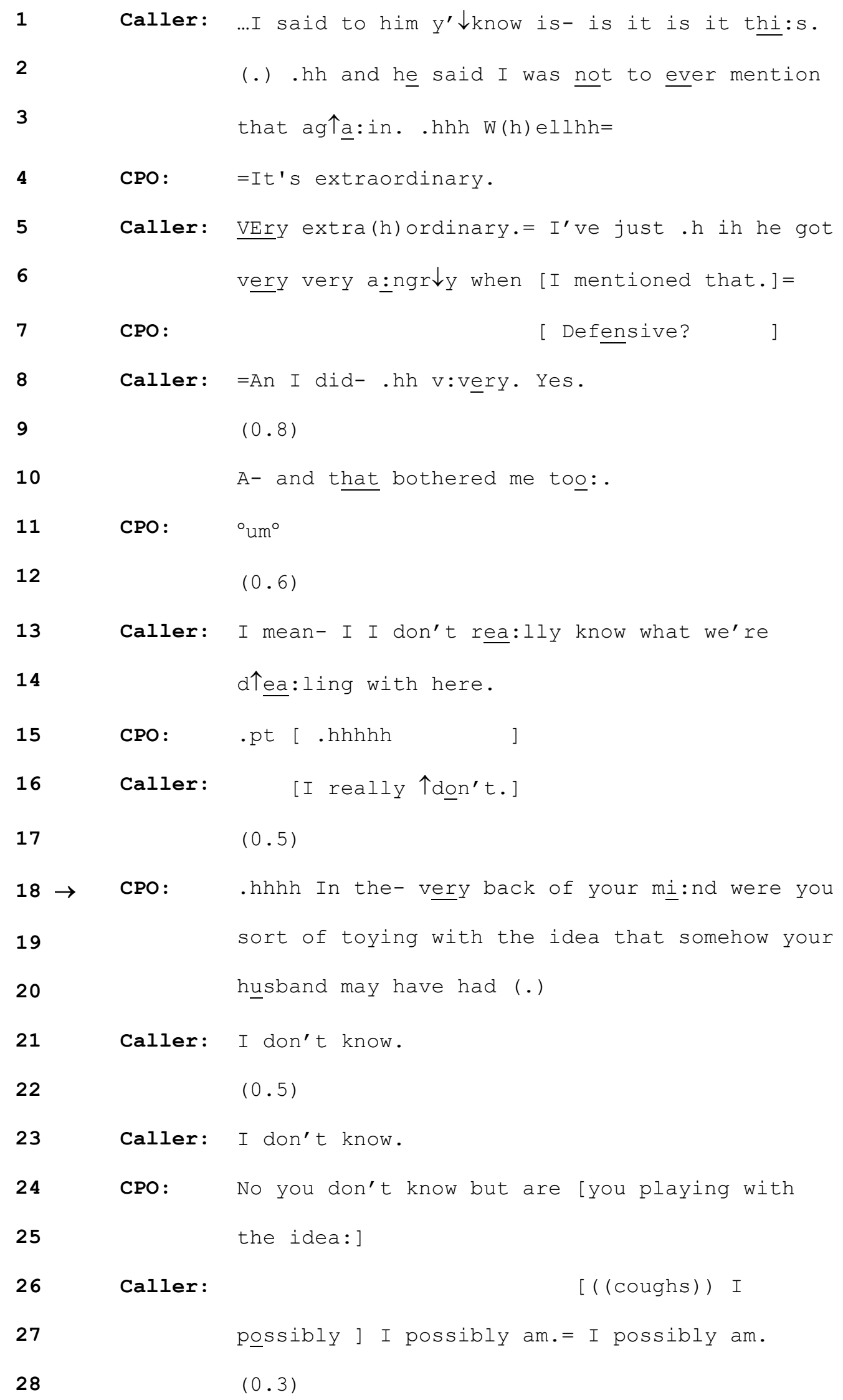




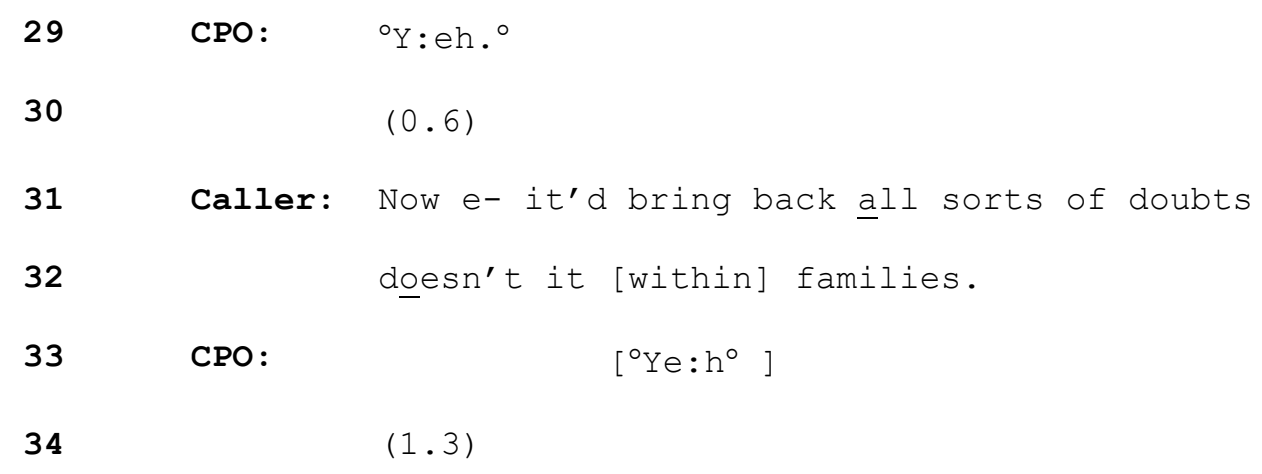

In line 18 the child protection officer ${ }^{7}$ uses the phrase "in the very back of your mind". We do not want to go into too much detail about its operation here. Suffice it to say that the counsellor may be delicately orienting to the possibility that the caller is concerned that her husband had been involved with sexual abusing family members when younger, but is reluctant to make that concern explicit. Or she may have come independently to such a possibility. Either way, by offering the construction that the caller may have been "toying with the idea" at the "back of your mind" she is able to present this as something that may or may not be being claimed or implied by the caller, while orienting to the fact that she has not explicitly and directly made such a claim up that point (over 43 minutes into the call). The counsellor thereby rather delicately moves on to talking about this issue. The mentalistic appeal, to unspoken thoughts in the head, is one practical and intelligible means available for doing this.

The point we want to note is that "the back of your mind" could be paraphrased in a non-Cartesian manner. But would such a paraphrase help? In what useful sense would it be equivalent? It would be confusing for the actual analysis, which is surely best done on the words uttered rather than on some different words. Moreover, what would be the justification for such a paraphrase? Ought we to take the counsellor as making some kind of philosophical assertion about the location of mental states, which might usefully be clarified by paraphrasing it as a behavioural disposition? Would the paraphrase then be taken to be 
what the counsellor "really means" in line $18 ?$ The problem is that we would then be starting to make a classic cognitivist move, of seeing speech as a consequence of underlying intentions. If we asked the counsellor to do her own paraphrase she might well produce a cognitivist one; after all she is trained in counselling where such cognitivism is commonplace. But substituting a paraphrase seems to us to be arbitrary, ironic, confused, and ultimately rather peculiar. We much prefer to study these actual words in their actual environment, and examine what they accomplish as common sense expressions.

This relates to another of Coulter's complaints, which is that discourse analysts believe in the "indefinite discursive flexibility or 'negotiability' of meanings" (1999: 172, original italics). For Coulter this "is not a matter of empiricism - of empirical adjudication based on appeals to whatever anyone might have actually said - but of logico-grammatical argument based on perspicuous instances of use" (1999: 172). Yet this depends on what the aim of analysis is. In our case it is not to identify "correct usage" but to study actual usage. Actual usage can involve a rhetorical finessing, working up, creative sequencing and construction of languages' resources to make claims, descriptions or accounts 'work'. Indeed, what counts as "correct usage" is something that itself can be up for dispute or reworking in interaction. Our point is that "correct usage" is by no means a straightforward criterion that stands outside of specific analysis. That is one of the things that has been documented in a wide range of studies. Coulter may claim that such examples are mistakes or incorrect in some way. However, the onus is surely on him to show this with these examples rather than merely state that this is the case.

Should discursive psychology be an empirical or a logical study? Coulter has pressed the virtues of logical or grammatical analysis. We do not believe that there is such a strong opposition to be made here, when it comes to analytic practice. Coulter glosses empirical research as research focused on the generation of statistical regularities (here "distributional 
criteria"). His claim that discursive psychology is empirical in this way is wide of the mark. A central element in the development of discursive psychology has been its critique of precisely such empirical approaches in experimental social psychology. Discursive psychology works through collections of instances, the close study of deviant cases and a major focus on participants' orientations (see Potter, in press). Yet clearly analysis of this kind cannot be adequately performed without the analyst drawing on their native linguistic competence.

Rather than come down on one side of the logic vs. empirical distinction, however, we would suggest two things. First, sociological studies of scientific knowledge show that empiricism itself - whether in physics or biochemistry or elsewhere - is a rather complicated thing, particularly when it is itself studied as part of practices and accounts, rather than as an abstraction about them (see Knorr Cetina, 1999). Second, it may be more useful to consider our respective analytic practices rather than what we write about them - i.e., what we claim about specific instances of language use, and how our claims are grounded. We tend to spend more time collecting and analysing actual examples, while Coulter tends to spend more time inventing illustrations for his arguments. 


\section{Endnotes}

We are tempted to put scare quotes around all our uses of these terms lest we are treated as having the belief that the words have inner referents simply on the basis of using the words themselves.

We are aware that we might be understood as making an ontological claim about some inner stuff here. For the record, again, we note that we do not take our study of the practice of describing, avowing, or attributing mental entities as committing us to the endorsement (or, in itself, of the denial) of such things.

This work has a number of similarities to Lynch \& Bogen's study Oliver North and his memory (Lynch \& Bogen, 1996; in press).

Although we would be unlikely to treat it as "theorizing", as if it thereby stood in some abstract relationship to the action. This points to another difference between our take on members' uses of mental predicates, and Coulter's notion of people "asserting" and "theorizing" matters, as if they were engaged in some form of philosophizing in opposition to Wittgenstein.

We are aware, of course, that Button \& Sharrock (1992), who sometimes work in a similar vein to Coulter, have criticized this tradition of work. For a detailed commentary and rebuttal of that critique see Potter (1996: 219-23). like to thank her and the NSPCC for permission to use it.

This is the NSPCC job description for their call-takers. We are not wanting to imply further about her actions than that. 


\section{References}

Billig, M. (1999a). Whose terms? Whose ordinariness? Rhetoric and ideology in conversation analysis. Discourse and Society 10: 543-558.

Billig, M. (1999b). Conversation analysis and the claims of naivety. Discourse and Society 10: 572-576.

Button, G., \& Sharrock, W. (1992). A disagreement over agreement and consensus in constructionist sociology. Journal for the Theory of Social Behaviour 23 (1), 125.

Collins, H.M. (1983). An empirical relativist programme in the sociology of scientific knowledge. In K.D. Knorr-Cetina \& M. Mulkay (Eds.), Science Observed: Perspectives on the Social Study of Science, pp. 85-113. London and Beverly Hills, CA: Sage.

Coulter, J. (1999). Discourse and mind. Human Studies, 22: 163-181.

Edwards, D. (1995). Two to tango: Script formulations, dispositions, and rhetorical symmetry in relationship troubles talk. Research on Language and Social Interaction, 28: 319-50.

Edwards, D. (1997). Discourse and cognition. London: Sage.

Edwards, D., Middleton, D., \& Potter, J. (1992). Toward a discursive psychology of remembering. The Psychologist, 5: 56-60.

Edwards, D. \& Potter, J. (1992). Discursive psychology. London: Sage.

Edwards, D. \& Potter, J. (2002). Discursive psychology. In A.W.McHoul \& M. Rapley (Eds), How to Analyse Talk in Institutional Settings: A Casebook of Methods, pp. 12-24. London: Continuum International. 
Edwards, D., \& Potter, J. (In press). Discursive psychology, mental states and descriptions. In H. te Molder \& J. Potter (Eds.), Talk and Cognition: Discourse, Cognition and Social Interaction, pp. **_**. Cambridge: Cambridge University Press.

Garfinkel, H. \& Sacks, H. (1970). On formal structures of practical actions. In J.C. McKinney \& E.A. Tiryakian (Eds.), Theoretical Sociology: Perspectives and Developments, pp. 337-366. New York: Appleton-Century-Crofts.

Harré, R., \& Gillett, G. (1994). The Discursive Mind. London: Sage.

Heritage, J.C. \& Watson, D.R. (1979). Formulations as conversational objects. In G. Psathas (Ed.), Everyday Language: Studies in Ethnomethodology, pp. 123-162. New York: Irvington.

Knorr Cetina, K. (1999). Epistemic Cultures: How the Sciences Make Knowledge. Harvard: Harvard University Press.

Lynch, M. \& Bogen, D. (1996). The Spectacle of History: Speech, Text, and Memory at the Iran-Contra Hearings. Durham, NC: Duke University Press.

Lynch, M. \& Bogen, D. (forthcoming). 'My memory has been shredded': A noncognitivist investigation of 'mental' phenomena. In H. te Molder \& J. Potter (Eds). Talk and Cognition: Discourse, Mind and Social Interaction. Cambridge: Cambridge University Press.

Peräkylä, A. (1995). AIDS Counselling: Institutional Interaction and Clinical Practice. Cambridge: Cambridge University Press.

Potter, J. (1996). Representing Reality: Discourse, Rhetoric and Social Construction. London: Sage.

Potter, J. (1998). Cognition as context (whose cognition?). Research on Language and Social Interaction, 31, 29-44. 
Potter, J. (In press). Discourse analysis. In M. Hardy \& A. Bryman (Eds.), Handbook of Data Analysis, pp. **_**. London: Sage.

Potter, J. \& Edwards, D. (2001a). Discursive social psychology. In W.P. Robinson \& H. Giles (Eds.), The New Handbook of Language and Social Psychology, pp. 103118. London: Wiley.

Potter, J. \& Edwards, D. (2001b). Sociolinguistics, cognitivism and discursive psychology. In N. Coupland, S. Sarangi, \& C. Candlin (Eds.), Sociolinguistics and Social Theory, pp. 88-103. London: Longman.

Sacks, H. (1992). Lectures on Conversation (Vols. I \& II, edited by G. Jefferson). Oxford: Basil Blackwell.

Schegloff, E.A. (1997). Whose text? Whose context? Discourse and Society, 8, 165187.

Schegloff, E.A. (1998). Reply to Wetherell. Discourse \& Society, 9: 413-416.

Schegloff, E.A. (1999a). "Schegloff's texts" as "Billig's data": A critical reply, Discourse and Society, 10: 558-572.

Schegloff, E.A. (1999b). Naivete vs sophistication or discipline vs self-indulgence: A rejoinder to Billig. Discourse and Society, 10 (4): 577-582.

Shotter, J. (1993). Conversational Realities: Constructing Life through Language. London: Sage.

Wetherell, M. (1998). Positioning and interpretative repertoires: Conversation analysis and post-structuralism in dialogue. Discourse and Society, 9: 387-412.

Wittgenstein, L. (1958). Philosophical Investigations. 2nd Edition, edited by G.E.M. Anscombe \& R. Rhees. Translated by G.E.M. Anscombe. Oxford: Blackwell. Wooffitt, R. (1992). Telling Tales of the Unexpected: The Organization of Factual Discourse. London: Harvester/Wheatsheaf. 
Woolgar, S. (1988). Science: The Very Idea. Chichester, UK: Ellis Horwood. 